\title{
Acute-onset Autoimmune Hepatitis in a Patient with Selective Immunoglobulin M Deficiency
}

\author{
Akitoshi Sano ${ }^{1}$, Jun Inoue ${ }^{1}$, Eiji Kakazu ${ }^{1}$, Masashi Ninomiya ${ }^{1}$, Tomoaki Iwata ${ }^{1}$, \\ Tatsuki Morosawa ${ }^{2}$, Satoshi Takai ${ }^{1}$, Takuya Nakamura ${ }^{1}$ and Atsushi Masamune ${ }^{1}$
}

\begin{abstract}
:
Selective immunoglobulin M deficiency (SIGMD) is an uncommon primary immunodeficiency disorder. We herein report an SIGMD patient with autoimmune hepatitis. A 21-year-old Japanese man was transferred to our hospital because of acute liver dysfunction. His serum IgM level was low, whereas those of IgG and IgA were normal, indicating that he had SIGMD. We diagnosed him with acute-onset autoimmune hepatitis, and his liver function test findings gradually recovered with corticosteroid administration. Although SIGMD with autoimmune diseases has been reported, the clinical features and pathogenesis have not yet been clarified. We have summarized previous reports on SIGMD patients with autoimmune diseases.
\end{abstract}

Key words: autoimmune hepatitis, selective immunoglobulin M deficiency

(Intern Med 58: 2185-2190, 2019)

(DOI: 10.2169/internalmedicine.2607-18)

\section{Introduction}

Selective immunoglobulin $\mathrm{M}$ deficiency (SIGMD) is a rare primary immunodeficiency disease associated with serious infectious diseases, autoimmune diseases and malignancies (1). In SIGMD patients, the serum immunoglobulin $\mathrm{M}$ (IgM) level is below two standard deviations of the mean, and the IgG and IgA levels are normal (1). Although a number of patients with SIGMD have been reported after Hobbs et al. first described young patients with SIGMD in 1967 (2), few large-scale studies have explored the prevalence of SIGMD.

Autoimmune hepatitis $(\mathrm{AIH})$, which is predominant in middle-age and elderly women, is a liver disease caused by the loss of tolerance to autoantigens (3). Although several studies have shown that autoimmune diseases are frequently present in adults with SIGMD, few SIGMD patients with AIH have been reported.

We herein report a young patient with SIGMD who experienced acute-onset $\mathrm{AIH}$ and review previous reports on SIGMD patients with autoimmune diseases.

\section{Case Report}

A 21-year-old Japanese man presented to a local hospital with fatigue and nausea. He had frequently experienced symptoms of a common cold for one year before visiting the hospital. Regarding his medical history, he had atopic dermatitis. He had no history of regular alcohol intake or smoking. He was not regularly taking any medicines, supplements, or illicit drugs.

He was admitted to the hospital because of liver dysfunction with high levels of serum aspartate aminotransferase (AST, $977 \mathrm{U} / \mathrm{L}$ ) and alanine aminotransferase (ALT, 2,191 U/L) (Table 1). He was negative for hepatitis B surface antigen, hepatitis $\mathrm{C}$ virus antibody, anti-nuclear antibody (ANA), and anti-liver kidney microsome type 1 (anti-LKM1) antibody. His serum level of $\operatorname{IgM}$ [reference range (RR) in the hospital: $33-190 \mathrm{mg} / \mathrm{dL}$ ] was low $(2 \mathrm{mg} / \mathrm{dL})$, whereas those of IgG (RR: 870-1,700 mg/dL) and IgA (RR: 110-410 $\mathrm{mg} / \mathrm{dL}$ ) were normal (1,095 and $175 \mathrm{mg} / \mathrm{dL}$, respectively). Abdominal computed tomography (CT) revealed periportal collar signs and edematous thickening of the gallbladder wall, indicating the presence of acute hepatitis (Fig. 1). CT

${ }^{1}$ Division of Gastroenterology, Tohoku University Graduate School of Medicine, Japan and ${ }^{2}$ Department of Gastroenterology, Saka General Hospital, Japan

Received: December 30, 2018; Accepted: February 18, 2019; Advance Publication by J-STAGE: April 17, 2019

Correspondence to Dr. Jun Inoue, jinoue-drgn@umin.net 
Table 1. Laboratory Data on Admission to the Previous Hospital.

\begin{tabular}{|c|c|c|c|}
\hline WBC & $7,100 / \mu \mathrm{L}$ & TSH & $0.77 \mu \mathrm{U} / \mathrm{dL}$ \\
\hline Neut & $60.8 \%$ & free $\mathrm{T} 3$ & $2.65 \mathrm{pg} / \mathrm{mL}$ \\
\hline Eosi & $20.1 \%$ & free $\mathrm{T} 4$ & $1.16 \mathrm{ng} / \mathrm{dL}$ \\
\hline Baso & $0.6 \%$ & $\mathrm{Na}$ & $141 \mathrm{mmol} / \mathrm{L}$ \\
\hline Mono & $9.1 \%$ & $\mathrm{~K}$ & $4 \mathrm{mmol} / \mathrm{L}$ \\
\hline Lymp & $9.4 \%$ & $\mathrm{Cl}$ & $103 \mathrm{mmol} / \mathrm{L}$ \\
\hline $\mathrm{RBC}$ & $4.87 \times 10^{6} / \mu \mathrm{L}$ & Glucose & $105 \mathrm{mg} / \mathrm{dL}$ \\
\hline $\mathrm{Hb}$ & $14.5 \mathrm{~g} / \mathrm{dL}$ & $\mathrm{HbAlc}$ & $5.6 \%$ \\
\hline Hct & $43.8 \%$ & $\operatorname{IgG}$ & $1,095 \mathrm{mg} / \mathrm{dL}$ \\
\hline PLT & $17.7 \times 10^{4} / \mu \mathrm{L}$ & $\operatorname{Ig} \mathrm{A}$ & $175 \mathrm{mg} / \mathrm{dL}$ \\
\hline РT\% & $96.5 \%$ & $\operatorname{IgM}$ & $2 \mathrm{mg} / \mathrm{dL}$ \\
\hline APTT & $31.9 \mathrm{sec}$ & ANA & $<40 \times$ \\
\hline Fibrinogen & $207 \mathrm{mg} / \mathrm{dL}$ & Anti-LKM-1 Ab & $<5.0$ index \\
\hline T-Bil & $1.6 \mathrm{U} / \mathrm{L}$ & Anti-ds DNA Ab & $2.4 \mathrm{U} / \mathrm{mL}$ \\
\hline D-Bil & $0.8 \mathrm{U} / \mathrm{L}$ & Anti-Sm Ab & $<1.0 \mathrm{U} / \mathrm{mL}$ \\
\hline AST & 977 U/L & AMA & $<20 \times$ \\
\hline ALT & $2,191 \mathrm{U} / \mathrm{L}$ & P-ANCA & $<1.0 \mathrm{U} / \mathrm{mL}$ \\
\hline LDH & $435 \mathrm{U} / \mathrm{L}$ & HBsAg & $(-)$ \\
\hline ALP & $828 \mathrm{U} / \mathrm{L}$ & $\mathrm{HBsAb}$ & $(-)$ \\
\hline $\mathrm{ChE}$ & $208 \mathrm{U} / \mathrm{L}$ & $\mathrm{HBcAb}$ & $(-)$ \\
\hline Amylase & $114 \mathrm{U} / \mathrm{L}$ & HBV DNA & $(-)$ \\
\hline BUN & $13.7 \mathrm{mg} / \mathrm{dL}$ & $\mathrm{HCV} \mathrm{Ab}$ & $(-)$ \\
\hline Creatinine & $0.69 \mathrm{mg} / \mathrm{dL}$ & HCV RNA & $(-)$ \\
\hline UA & $6.6 \mathrm{mg} / \mathrm{dL}$ & HAV IgM & $(-)$ \\
\hline $\mathrm{TP}$ & $6.8 \mathrm{mg} / \mathrm{dL}$ & HEV IgA & $(-)$ \\
\hline Albumin & $4.4 \mathrm{mg} / \mathrm{dL}$ & EBV EA IgG & $(-)$ \\
\hline TG & $135 \mathrm{mg} / \mathrm{dL}$ & EBV VCA IgM & $(-)$ \\
\hline T-Cho & $157 \mathrm{mg} / \mathrm{dL}$ & EB VCA IgG & $(+)$ \\
\hline Ferritin & $991 \mathrm{ng} / \mathrm{mL}$ & EB EBNA & $(-)$ \\
\hline NH3 & $39 \mu \mathrm{g} / \mathrm{dL}$ & HSV IgM & $(-)$ \\
\hline AFP & $2.6 \mathrm{ng} / \mathrm{mL}$ & VZV IgM & $(-)$ \\
\hline CEA & $2.0 \mathrm{ng} / \mathrm{mL}$ & VZV IgG & $(+)$ \\
\hline \multirow[t]{2}{*}{ CA19-9 } & $9.7 \mathrm{U} / \mathrm{mL}$ & B19 IgM & $(-)$ \\
\hline & & CMV IgM & $(-)$ \\
\hline
\end{tabular}

WBC: white blood cell, Neut: neutrophil, Eosi: eosinophil, Baso: basophil, Mono: monocyte, Lymp: lymphocyte, RBC: red blood cell, Hb: hemoglobin, Hct: hematocrit, PLT: platelet, PT: prothrombin time, APTT: activated partial thromboplastin time, T-Bil: total bilirubin, D-Bil: direct bilirubin, AST: aspartate aminotransferase, ALT: alanine aminotransferase, LDH: lactate dehydrogenase, ALP: alkaline phosphatase, ChE: cholinesterase, BUN: blood urea nitrogen, UA: uric acid, TP: total protein, TG: triglycerides, T-Cho: total cholesterol, AFP: alpha-fetoprotein, CEA: carcinoembryonic antigen, CA19-9: carbohydrate antigen 19-9, TSH: thyroid-stimulating hormone, Ig: immunoglobulin, ANA: anti-nuclear antibody, Anti-LKM-1 Ab: anti-liver kidney microsome type 1 antibody, Anti-ds DNA Ab: anti-double stranded DNA IgG antibody, Anti-Sm Ab: anti-Smith antibody, AMA: anti-mitochondrial antibody, p-ANCA: myeloperoxidase-anti-neutrophil cytoplasmic antibody, HBs Ag: hepatitis B surface antigen, HBs Ab: hepatitis B surface antibody, HBc: hepatitis B core, HCV: hepatitis C virus, HAV: hepatitis A virus, HEV: hepatitis E virus, EBV: Epstein-Barr virus, EA: early antigen, VCA: virus capsid antigen, EBNA: EBV nuclear antigen, HSV: herpes simplex virus, VZV: varicella zoster virus, B19: Parvovirus B19, CMV: cytomegalovirus

did not show any signs of malignant disease. A percutaneous liver biopsy was performed nine days after his admission, and the histological examination did not show lobular/ portal plasma cell infiltration, fibrosis, or centrilobular in- flammation/necrosis, but moderate lobular inflammation and interface hepatitis in the portal areas was found (Fig. 2). No emperipolesis, cobblestone appearance, or rosette formation of hepatocytes was noted.

He was diagnosed with acute-onset AIH based on the pathological findings, and steroid therapy with prednisolone (PSL, $50 \mathrm{mg} /$ day) was started, with the dose later tapered (Fig. 3). However, while his liver function gradually recovered, the serum aminotransferase levels were still abnormal despite the patient taking $30 \mathrm{mg} /$ day PSL. At 36 days after his admission, he was transferred to our hospital for further examinations and treatment.

On admission to our hospital, he was $170 \mathrm{~cm}$ in height and $53.8 \mathrm{~kg}$ in weight with a blood pressure of 103/67 $\mathrm{mmHg}$, pulse 62 beats per minute and regular, and body temperature $36.4^{\circ} \mathrm{C}$. His consciousness was lucid. He did not have icterus or abdominal symptoms.

Regarding laboratory data, his serum IgM level (RR in our hospital: $33-183 \mathrm{mg} / \mathrm{dL})$ was extremely low $(<4 \mathrm{mg} / \mathrm{dL})$ although the serum IgG (RR: 861-1,747 mg/dL) and IgA (RR: $93-393 \mathrm{mg} / \mathrm{dL}$ ) levels were almost normal $(867 \mathrm{mg} / \mathrm{dL}$ and $150 \mathrm{mg} / \mathrm{dL}$, respectively), as the laboratory data from the previous hospital had shown. A flow cytometric analysis of the peripheral blood revealed normal rates of CD4+ and CD8+ T lymphocytes (36.8\% and $26.3 \%$, respectively) and CD19+ B lymphocytes (28.1\%). He was positive for antiEpstein Barr virus capsid antigen $\mathrm{IgG}$, and anti-Varicella Zoster Virus IgG, indicating that his specific IgG producibility was normal. Lymphocyte blastoid transformation by process hazard analysis (PHA) did not show dysfunction of $\mathrm{T}$ cells (PHA+: 16,604 cpm, control: $113 \mathrm{cpm}$ ). These results indicated that he had SIGMD as the underlying disease.

The laboratory data also showed high levels of serum AST (66 U/L) and ALT (188 U/L). According to the revised scoring system of the International Autoimmune Hepatitis Group (IAIHG) (4), he was scored as probable AIH (score 12). Because some human leukocyte antigen (HLA) types have been reported to be risk factors for $\mathrm{AIH}$, we determined his HLA haplotype, and it was revealed that he had DRB1*04:05 and DQB1*04:01, both of which have been reported to be associated with $\mathrm{AIH}$ (5). Considering these laboratory data and pathological findings along with the evidence from previous reports that adults with SIGMD frequently develop autoimmune diseases, he was diagnosed as having acute-onset AIH with SIGMD.

We continued steroid therapy (PSL $30 \mathrm{mg} /$ day) and tapered the dose. During the tapering of the corticosteroid dose, ursodeoxycholic acid (UDCA, $600 \mathrm{mg} /$ day) was added, and the liver function gradually recovered. During the treatment period, the serum level of $\operatorname{IgM}$ was not changed, while that of $\operatorname{IgG}$ was slightly reduced. On the 26th day after the admission to our hospital, he was discharged with PSL (15 mg/day) and UDCA (600 mg/day). Eight days after discharge, his serum AST and ALT levels increased once again (177 and $485 \mathrm{U} / \mathrm{L}$, respectively). The 

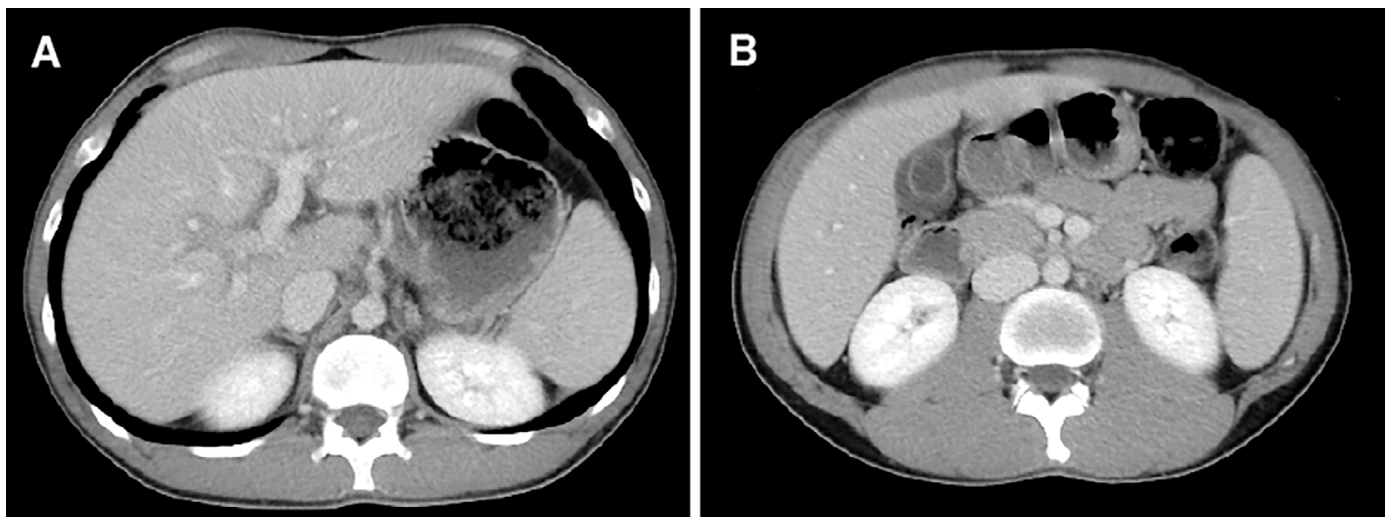

Figure 1. Abdominal contrast enhanced computed tomography scans. (A) Areas of low attenuation around the portal vein and its branches (periportal collar signs) were recognized. (B) Edematous thickening of the gallbladder wall appeared.

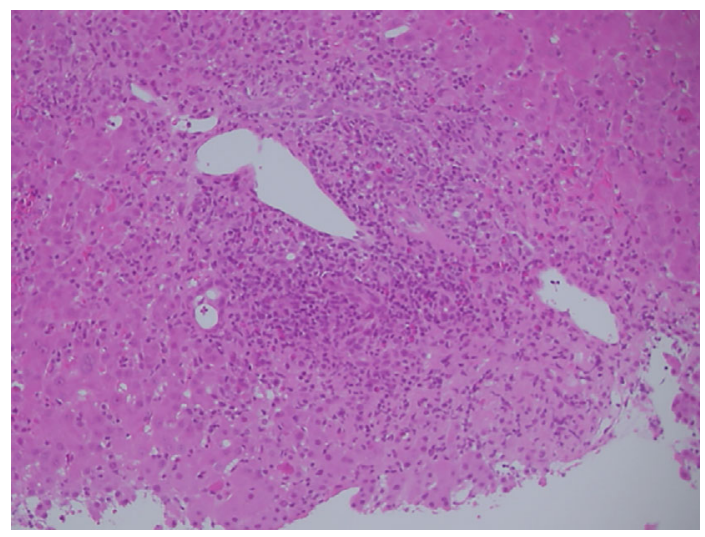

Figure 2. An image of a liver biopsy specimen (Hematoxylin and Eosin staining, original magnification $\times 200$ ). The presence of interface hepatitis with dense portal lymphocyte infiltrate disrupting the limiting plate is shown.

dose of PSL was therefore increased to $30 \mathrm{mg} /$ day and tapered again more slowly. His serum aminotransferase levels subsequently decreased gradually, and six months after the start of PSL, they had normalized.

\section{Discussion}

SIGMD is a disorder characterized by a low level of serum IgM and normal IgG and IgA levels with a normal T cell function. Some patients with SIGMD may be asymptomatic, but more commonly, the frequency of infections with microbes is reported to be higher than in healthy people (6). There have been few large-scale studies concerning the prevalence of patients with SIGMD. Entezari et al. reported that the prevalence of patients with SIGMD was $0.37 \%$ in the screening of a blood bank of more than 3,000 healthy adults (7). Another cohort study obtained from a retrospective analysis based on a PubMed database reported that the prevalence of SIGMD was $0.26 \%$ (8). A complete absence $(<4 \mathrm{mg} / \mathrm{dL})$ of serum IgM is relatively uncommon; indeed, in a cohort of 55 patients with SIGMD, only 4 patients had complete absence of serum IgM (1).

Although familial cases of SIGMD have been reported (9), no inheritance patterns or responsible genes have yet been identified. The European Society for Immunodeficiencies Registry defines SIGMD as a serum IgM level repeatedly below two standard deviations of normal with normal levels of serum IgA, IgG, and IgG subclasses, an absence of $\mathrm{T}$ cell defects, and an absence of causative external factors (http://www.esid.org). Our case showed a complete absence of serum IgM repeatedly and almost normal IgG and $\operatorname{IgA}$. In addition, a flow cytometric analysis of peripheral blood revealed almost normal rates of CD4+ and CD8+ T lymphocytes and CD19+ B lymphocytes, and lymphocyte blastoid transformation by PHA showed no dysfunction of $\mathrm{T}$ cells. External factors causing SIGMD were not found. Based on these findings, we diagnosed the present patient with SIGMD.

$\mathrm{AIH}$ is a disease of the hepatic parenchyma that can present in acute or chronic forms, in common with many autoimmune diseases. AIH is associated with non-organ-specific antibodies in the context of hepatic autoimmunity (10). In Japan, a study in a certain region revealed that the incidence and prevalence of AIH were 2.23 and 23.4 per 100,000, respectively (age-standardized to the Japanese population) (11). AIH often presents as a chronic disease; however, it can also have an acute presentation (12). A nationwide survey in Japan revealed that acute hepatitis was seen in $11.7 \%$ of patients with AIH (13). Acute AIH has some characteristics: (a) recent onset ( $<30$ days), (b) significant clinical symptoms, (c) remarkable biochemical elevations (serum bilirubin level and/or aminotransferase levels) (12). Although serum IgG or autoantibody levels are frequently elevated in chronic AIH, they may not be elevated in patients with acute-onset $\mathrm{AIH}(12,14-16)$. Therefore, these laboratory data are sometimes not reliable. The histological features are also varied, and previous studies have reported that lobular/ portal inflammation and interface hepatitis were frequently observed in patients with acute-onset $\operatorname{AIH}(17,18)$. The 


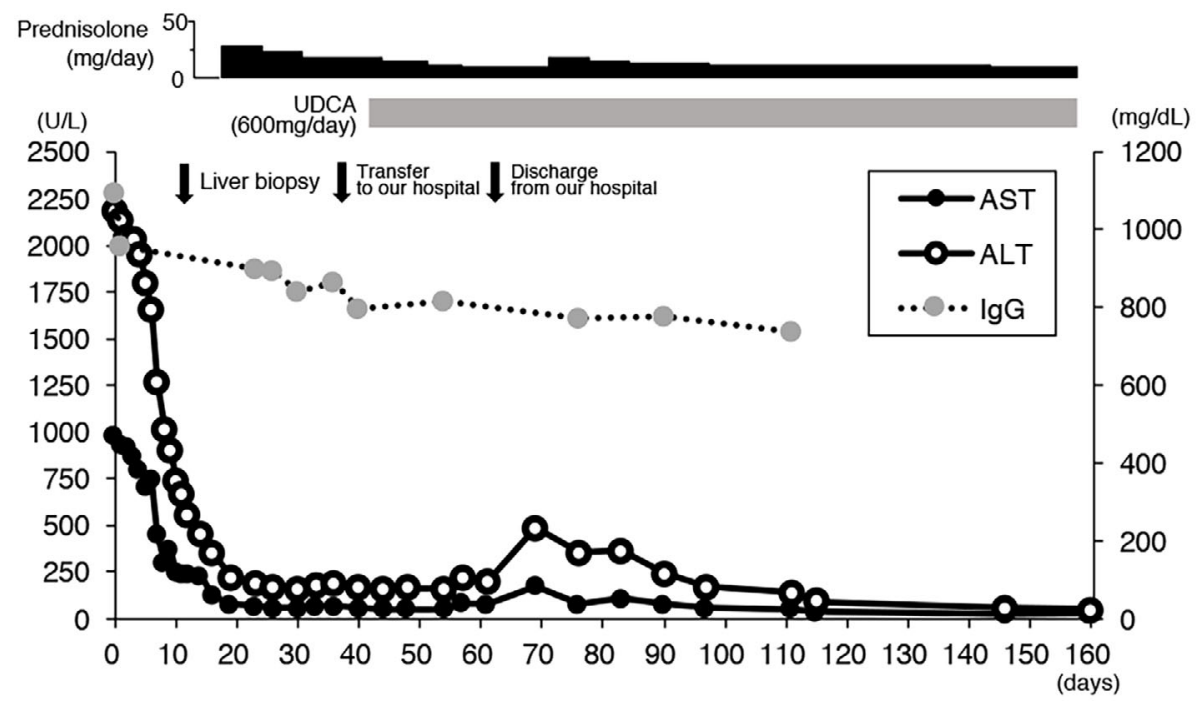

Figure 3. The clinical course of the present case after admission to the previous hospital. ALT: alanine aminotransferase, AST: aspartate aminotransferase, IgG: Immunoglobulin G, UDCA: ursodeoxycholic acid

IAIHG criteria have been often used for the diagnosis of AIH (4), but the scoring system may be also unreliable in patients with acute-onset AIH. A previous study reported that the frequency of an overall diagnosis of $\mathrm{AIH}$ by the IAIHG system among 70 patients with fulminant liver failure caused by acute-onset AIH was $40 \%$ (19). Therefore, the diagnosis of acute-onset AIH needs to be made comprehensively from various viewpoints.

The present patient showed acute-onset clinical symptoms of fatigue and nausea and markedly elevated serum aminotransferase levels, suggesting he had acute hepatitis. Evidence of a viral infection, alcoholic hepatitis, druginduced liver injury, or other liver diseases was absent. Although he showed atypical findings of $\mathrm{AIH}$, with the absence of elevated levels of serum IgG and autoantibodies, he was defined as probable AIH according to the revised IAIHG scoring system, and the histological findings were consistent with the features of AIH. Furthermore, he had HLA-DR/DQ types, which have been reported to be associated with AIH in Japan (5). In addition, autoimmune diseases are more frequent in patients with SIGMD than in the general population (1), with an estimated rate of $8 \%$ according to a long-term follow-up study (6). Given the above, we diagnosed him with acute-onset AIH and started corticosteroid therapy. A previous study noted that, in acute-onset AIH, the response rate to PSL therapy ranges from $36 \%$ to $100 \%$ (12). In our case, the reaction to corticosteroid treatment was relatively good, and his serum aminotransferase levels have remained adequate with oral low-dose of PSL. This good response to steroid therapy also supports the diagnosis of AIH.

Previous reports of autoimmune diseases associated with SIGMD on PubMed are presented in Table 2 (20-30). Although collagen diseases or thyroid diseases with SIGMD have been reported relatively frequently, there is only one case report of AIH with SIGMD. No other cases of AIH accompanied by the "complete" absence of serum IgM have been reported.

The mechanisms underlying autoimmunity with SIGMD are unknown. One suggested possibility is cross-linking of $\operatorname{IgM} \mathrm{Fc}$ receptor $(\mathrm{Fc} \mu \mathrm{R})$ and $\mathrm{B}$-cell receptor $(\mathrm{BCR})$ by $\operatorname{IgM}$ autoantibody-self-antigen complexes, causing the induction of anergy (20). Mouse mutants for Fc $\mu \mathrm{R}$ showed impairment in specific responses of $\mathrm{IgG}$ antibodies against T-dependent and T-independent antigens, resulting in the development of autoimmunity (31). In addition, the deficiency of CXCR3+ B-cells in SIGMD patients and a relationship between CXCR3 + cells and autoimmunity have been reported $(32,33)$. Other potential mechanisms reported in the literature include the loss of central tolerance as a result of BCR editing, loss of peripheral tolerance due to a deficiency of isotype-specific regulatory lymphocytes, and an impaired clearance of apoptotic cells (1). In the present AIH case, high levels of serum IgG or autoantibodies were not seen, probably because AIH was caused by the loss of tolerance or an impairment of anergy resulting from a deficiency in IgM by the mechanisms described above, which differed from those in patients with typical AIH.

We herein report a rare case of a young man who developed acute-onset AIH with SIGMD. Corticosteroid therapy has been effective, and the state of AIH has been wellcontrolled. Although the risk of serious infections is regarded as smaller in adult patients with SIGMD than in pediatric patients (1), an adult patient with a life-threatening infection has been reported (34). We should carefully treat the complications of infectious diseases because of the need for low-dose long-term corticosteroid administration. Because cases of autoimmune diseases, especially AIH, accom- 
Table 2. Reported Cases of Autoimmune Diseases with SIGMD.

\begin{tabular}{|c|c|c|c|c|c|}
\hline $\begin{array}{c}\text { Age } \\
\text { (years) }\end{array}$ & Gender & Associated disease & $\underset{(\mathrm{mg} / \mathrm{dL})}{\operatorname{IgM}}$ & $\underset{(\mathrm{mg} / \mathrm{dL})}{\mathrm{IgG}}$ & Reference \\
\hline 51 & Female & SLE & 10 & 2,340 & (21) \\
\hline 43 & Female & SLE & 5 & 1,426 & (22) \\
\hline 37 & Female & SLE & 15 & 1,506 & (22) \\
\hline 33 & Female & SLE & 17 & 1,532 & (22) \\
\hline 47 & Female & SLE & 23 & 1,567 & (22) \\
\hline 41 & Female & SLE & 25 & 1,900 & (22) \\
\hline 42 & Female & SLE & 28 & 1,316 & (22) \\
\hline 36 & Male & SLE & 30 & 1,267 & (22) \\
\hline 59 & Female & SLE & 32 & 2,546 & (22) \\
\hline 30 & Female & SLE & 37 & 1,109 & $(22)$ \\
\hline 63 & Female & SLE & 43 & 1,319 & $(22)$ \\
\hline 36 & Female & SLE & 44 & 1,226 & (22) \\
\hline 55 & Female & SLE & 44 & 1,441 & (22) \\
\hline 29 & Female & SLE & 25 & 1,597 & (23) \\
\hline 30 & Male & SLE & 6 & 936 & (23) \\
\hline 73 & Female & SLE & 12 & 1,180 & (24) \\
\hline 77 & Female & SLE & 18 & 1,120 & (24) \\
\hline 23 & Male & Celiac disease & 48 & 2,100 & (25) \\
\hline 26 & Male & Celiac disease & 27 & 1,700 & (25) \\
\hline 75 & Male & Celiac disease & 48 & 1,700 & (25) \\
\hline 52 & Male & Celiac disease & $<32$ & NA & (20) \\
\hline 63 & Female & Sjögren's syndrome & $<5$ & 3,030 & (24) \\
\hline 53 & Female & Sjögren's syndrome & 16 & 1,500 & (24) \\
\hline 70 & Male & Hashimoto's disease & $<3$ & 1,972 & (25) \\
\hline 50 & Female & Hashimoto's disease & 34 & 921 & (26) \\
\hline 39 & Female & Hypothyroidism & 16 & 729 & (26) \\
\hline 65 & Male & Hypothyroidism & $<5$ & 1,350 & (24) \\
\hline 67 & Male & Hypothyroidism & 27 & NA & (27) \\
\hline 53 & Female & Rheumatoid arthritis & 17 & 2,159 & (23) \\
\hline 46 & Female & Rheumatoid arthritis & 39 & 985 & (26) \\
\hline 68 & Female & CREST syndrome & 37 & NA & (27) \\
\hline 57 & Male & Autoimmune glomerulonephritis & 34 & 1,500 & (28) \\
\hline 34 & Male & Psoriasis pustulosa & 1 & 1,314 & (29) \\
\hline 64 & Female & Autoimmune hepatitis & 11 & 2,942 & $(30)$ \\
\hline 21 & Male & Autoimmune hepatitis & 2 & 1,095 & Present case \\
\hline
\end{tabular}

SIGMD: selective immunoglobulin M deficiency, IgM: immunoglobulin M, IgG: immunoglobulin G, SLE: systematic lupus erythematosus, NA: not available

panied by SIGMD have seldom been reported, further studies are needed to reveal the etiology, pathogenesis, and clinical features.

\section{The authors state that they have no Conflict of Interest (COI).}

\section{References}

1. Gupta S, Gupta A. Selective IgM deficiency-an underestimated primary immunodeficiency. Front Immunol 8: 1-7, 2017.

2. Hobbs JR, Milner RDG, Watt PJ. Gamma-M deficiency predisposing to meningococcal septicaemia. Br Med J 4: 583-586, 1967.

3. Sahebjam F, Vierling JM. Autoimmune hepatitis. Front Med 9: 187-219, 2015.

4. Alvarez F, Berg PA, Bianchi FB, et al. International Autoimmune Hepatitis Group Report: review of criteria for diagnosis of autoimmune hepatitis. J Hepatol 31: 929-938, 1999.
5. Umemura T, Katsuyama Y, Yoshizawa K, et al. Human leukocyte antigen class II haplotypes affect clinical characteristics and progression of type 1 autoimmune hepatitis in Japan. PLoS ONE 9: e100565, 2014

6. Louis AG, Gupta S. Primary selective IgM deficiency: an ignored immunodeficiency. Clin Rev Allergy Immunol 46: 104-111, 2014.

7. Entezari N, Adab Z, Zeydi M, et al. The prevalence of selective immunoglobulin $\mathrm{M}$ deficiency (SIgMD) in Iranian volunteer blood donors. Hum Immunol 77: 7-11, 2016.

8. Goldstein MF, Goldstein AL, Dunsky EH, Dvorin DJ, Belecanech GA, Shamir K. Selective IgM immunodeficiency: retrospective analysis of 36 adult patients with review of the literature. Ann Allergy Asthma Immunol 97: 717-730, 2006.

9. Jones DM, Tobin BM, Butterworth A. Three cases of meningococcal infection in a family, associated with a deficient immune response. Arch Dis Child 48: 742-743, 1973.

10. Heneghan MA, Yeoman AD, Verma S, Smith AD, Longhi MS. Autoimmune hepatitis. Lancet 382: 1433-1444, 2013. 
11. Yoshizawa $\mathrm{K}$, Joshita $\mathrm{S}$, Matsumoto A, et al. Incidence and prevalence of autoimmune hepatitis in the Ueda area, Japan. Hepatol Res 46: 878-883, 2016

12. Wang Q, Yang F, Miao Q, Krawitt EL, Gershwin ME, Ma X. The clinical phenotypes of autoimmune hepatitis: a comprehensive review. J Autoimmun 66: 98-107, 2016.

13. Takahashi A, Arinaga-Hino T, Ohira H, et al. Autoimmune hepatitis in Japan: trends in a nationwide survey. J Gastroenterol 52: 631-640, 2017.

14. Ohira $\mathrm{H}$, Abe $\mathrm{K}$, Takahashi A, Watanabe H. Autoimmune hepatitis: recent advances in the pathogenesis and new diagnostic guidelines in Japan. Intern Med 54: 1323-1328, 2015.

15. Ohira H. Current status and issues of autoimmune hepatitis in Japan. Kanzo 56: 167-178, 2015 (in Japanese).

16. Joshita $S$, Yoshizawa $K$, Umemura $T$, et al. Clinical features of autoimmune hepatitis with acute presentation: a Japanese nationwide survey. J Gastroenterol 53: 1079-1088, 2018.

17. Okano N, Yamamoto K, Sakaguchi K, et al. Clinicopathological features of acute-onset autoimmune hepatitis. Hepatol Res 25 : 263-270, 2003

18. Nguyen Canh H, Harada K, Ouchi $\mathrm{H}$, et al. Acute presentation of autoimmune hepatitis: a multicentre study with detailed histological evaluation in a large cohort of patients. J Clin Pathol 70: 961969, 2017.

19. Yeoman AD, Westbrook RH, Al-Chalabi T, et al. Diagnostic value and utility of the simplified International Autoimmune Hepatitis Group (IAIHG) criteria in acute and chronic liver disease. Hepatology 50: 538-545, 2009.

20. Chen S, Shamriz O, Toker O, Fridlender ZG, Tal Y. Recurrent eosinophilic pneumonia in a patient with isolated immunoglobulin M deficiency and celiac disease. Isr Med Assoc J 17: 526-527, 2015.

21. Ohno T, Inaba M, Kuribayashi K, Masuda T, Kanoh T, Uchino H. Selective IgM deficiency in adults: phenotypically and functionally altered profiles of peripheral blood lymphocytes. Clin Exp Immunol 68: 630-637, 1987.

22. Saiki O, Saeki Y, Tanaka T, et al. Development of selective IgM deficiency in systemic lupus erythematosus patients with disease of long duration. Arthritis Rheum 30: 1289-1292, 1987.

23. Inoue T, Okumura $Y$, Shirahama M, et al. Selective partial IgM deficiency: functional assessment of $\mathrm{T}$ and $\mathrm{B}$ lymphocytes in vitro. J Clin Immunol 6: 130-135, 1986
24. Chovancova Z, Kralickova P, Pejchalova A, et al. Selective IgM deficiency: clinical and laboratory features of 17 patients and a review of the literature. J Clin Immunol 37: 559-574, 2017.

25. Blecher TE, Brzechwa-Ajdukiewicz A, McCarthy CF, Read AE. Serum immunoglobulins and lymphocyte transformation studies in coeliac disease. Gut 10: 57-62, 1969.

26. Yel L, Ramanuja S, Gupta S. Clinical and immunological features in IgM deficiency. Int Arch Allergy Immunol 150: 291-298, 2009.

27. Janssen LMA, Macken T, Creemers MCW, Pruijt JFM, Eijk JJJ, Vries E. Truly selective primary IgM deficiency is probably very rare. Clin Exp Immunol 191: 203-211, 2018.

28. Antar M, Lamarche J, Peguero A, Reiss A, Cole S. A case of selective immunoglobulin $\mathrm{M}$ deficiency and autoimmune glomerulonephritis. Clin Exp Nephrol 12: 300-304, 2008.

29. Yamasaki T. Selective IgM deficiency: functional assessment of peripheral blood lymphocytes in vitro. Intern Med 31: 866-870, 1992.

30. Arahata M, Tajiri K, Nomoto $K$, Tsuneyama $K$, Minami $S$, Shimizu Y. A novel type of selective immunoglobulin M deficiency in a patient with autoimmune liver cirrhosis with recurrent hepatocellular carcinoma: a case report and review of the literature. Int Arch Allergy Immunol 161: 91-96, 2013.

31. Gupta S, Agrawal S, Gollapudi S, Kubagawa H. Fc $\mu$ R in human B cell subsets in primary selective IgM deficiency, and regulation of Fc $\mu \mathrm{R}$ and production of natural IgM antibodies by IGIV. Hum Immunol 77: 1194-1201, 2016.

32. Louis AG, Agrawal S, Gupta S. Analysis of subsets of B cells, Breg, CD4Treg and CD8Treg cells in adult patients with primary selective IgM deficiency. Am J Clin Exp Immunol 5: 21-32, 2016.

33. Henneken M, Dörner T, Burmester GR, Berek C. Differential expression of chemokine receptors on peripheral blood B cells from patients with rheumatoid arthritis and systemic lupus erythematosus. Arthritis Res Ther 7: R1001-R1013, 2005.

34. Hong R, Gupta S. Selective immunoglobulin M deficiency in an adult with Streptococcus pneumoniae sepsis and invasive aspergillosis. J Investig Allergol Clin Immunol 18: 214-218, 2008.

The Internal Medicine is an Open Access journal distributed under the Creative Commons Attribution-NonCommercial-NoDerivatives 4.0 International License. To view the details of this license, please visit (https://creativecommons.org/licenses/ by-nc-nd/4.0/).

(C) 2019 The Japanese Society of Internal Medicine

Intern Med 58: 2185-2190, 2019 